\title{
DEVELOPMENT OF AN ENHANCED EXAM MANAGEMENT
}

\author{
Ike Mgbeafulike \\ Department of Computer Science \\ Chukwuemeka Odumegwu Ojukwu University, \\ Uli, Anambra, Nigeria
}

\begin{abstract}
The technological advancement in IT has brought about the need for computer usage in all areas of human life and endeavors, education sector also. The traditional method of conducting exams is often characterized by questions leakages, human errors during marking of students scripts and recording of students scores. This work, An Enhanced Exam Management System was, therefore, born out of the will to solve the problems plaguing the conventional (paper-based) examination system by providing a campus-wide service for e-assessment devoid of dishonest conduct and equally enhances quick feedback. The developed system which uses a combination of HTML, PHP, MySQL reduces the proportion of workload on examination, grading and reviewing on the part of examiners. The system also enables the release of exam results in record time and without errors. Thus, this system can serve as a solution for mass education evaluation and offers many features that cannot be implemented in paper-based system.
\end{abstract}

Keywords: IT, Enhanced exam management system, campus-wide service, e-assessment, paper-based systems.

\section{INTRODUCTION}

Automation in organizations (public and private) have been found very common with the rapid development in information technology and due to automation all the works is done by computers. It makes work easier, faster $\&$ reliable as compared to the previous way of working. An important aspect of the web technologies is in the development of webbased testing and assessment (Iyilade \& Adekunle, 2005). Before the massive growth of IT, students academic performances were evaluated via paper-based system of assignments, tests and assessment. Since recent progress Information Technology (IT) has advanced, educational products are now available electronically and new methods of educational assessment have emerged. An Enhanced Exam Management System offers greater flexibility than the traditional paper-based approach. The e-Examination system rides on the success of Information and Communication Technology (ICT) and its features, consistency, reliability and security. The system simplifies the examination process by automatic marking and computer aided control to reduce the

\author{
Ezechi Chekwube \\ Department of Computer Science \\ Chukwuemeka Odumegwu Ojukwu University, \\ Uli, Anambra, Nigeria
}

complex paper work (Meng \& Lu, 2011). The current adoption of ICT towards promoting distance education where distance between learners and instructors is no longer an issue, An Enhanced Exam Management System is a solution for mass education evaluation. The system is based on a Browser/Server framework which carries out the examination and auto-grading for objective questions. The system facilitates conducting exams, collection of answer scripts, automatic marking and the production of reports for the assessment. The system developed reduces the workload on examination, grading and reviewing. It also has the possibility to reduce drastically examination malpractice as students taking the exam are authenticated online in a real-time manner and their results are released few minutes after completing the examination because where the lecturer would spend weeks of marking scripts and grading manually, the computer would grade the students as soon as they finish their paper, get their stored continuous assessment and produce their results. It also boosts effective distance education as students taking the exam can write examination in any part of the world and get their results instantly.

\section{SUMMARY OF BACKGROUND}

The system which the developer is proposing is an "An Enhanced Examination Management System". This system is used to solve an area of problems faced in the education organization. This system is used to conduct an objectivebased/multiple-choice based online exam; it will also generate the question paper for the exam (which is a common method of conducting an exam). It will generate random questions for each candidate, it will also assess the exam and generate a result for the candidate at the same time after completing an exam. This system will generate all the required reports to keep the record in files. An examination is a big test not just for the person who takes the exams but also for the teacher/lecturer and management who arrange these exams. The traditional method of exams involves the paperwork, then checking the papers, arranging the marks, and then finally feeding the results in a computer for printing the reports. This system removes most of the drawback that was in the traditional method. The exams are online so the user can write the exams from anywhere around the world. Also, the exam results can be calculated automatically just at the end of 


\section{International Journal of Engineering Applied Sciences and Technology, 2021 \\ Vol. 5, Issue 12, ISSN No. 2455-2143, Pages 33-38 \\ Published Online April 2021 in IJEAST (http://www.ijeast.com)}

exams. It also minimizes the error in calculating results that humans do most of the time. Also, the most important benefit of making exams online is that data is saved in a structured format which can be used for detail report to make reports, charts, and presentation. A person can check the question paper that was published 10 years ago in an instant. Some challenges led to the development of the system which includes but not limited to (i) lot of copies of question papers have to be made. (ii) The examination candidates can be stopped before the allotted time for the examination by the invigilators and (iii) answer scripts can be misplaced during submission which will result in the candidate results not being recorded. This paper aims to develop an enhanced exam management system. It will help to conduct assessment and examination efficiently and reduce the tedious paperwork and also provide instant accessibility of examination results once the examination exercise is over.

\section{LITERATURE REVIEW}

There are several researches and projects focused on developing better ways to manage exam systems and elearning system. Some of these researches focused on various sections of the system and these includes Schramm (2008) looked at e-learning web based system that could simply offer and grade mathematical questions with infinite continued existence. Therefore it needs the capability for input and output of mathematical formulas, the dynamic generation of plots and the generation of random expressions and numbers. The idea of the generic software is to present an empty templates to the teacher who would like to develop his required e-examination for the needful topic (mathematics, language, science, etc) and desired set of exam kinds (multiple choices, matching between words, fill in blanks, etc). Webbased Examination System is an effective solution for mass education evaluation (Zhenming et al, 2003). They developed a novel online examination system based on a Browser/Server framework which carries out the examination and autograding for objective questions and operating questions, such as programming, operating Microsoft Windows, editing Microsoft Word, Excel and PowerPoint, etc. It has been applied to the distance evaluation of basic operating skills of computer science, such as the course of computer skills in universities and the nationwide examination for the high school graduates in Zhejiang Province, China. Another paper (He, 2006) presents a web-based educational assessment system by applying Bloom's taxonomy to evaluate student learning outcomes and teacher instructional practices in real time. The system performance is rather encouraging with experimentation in science and mathematics courses of two local high schools. Another paper proposed web based online examination system (Rashad et al, 2010). The system carries out the examination and auto-grading for students exams. The system facilitates conducting exams, collection of answers, auto marking the submissions and production of reports for the test. It was used via the internet and is

Therefore suitable for local and remote examination. The system could help lecturers, instructors, teachers and others who are willing to create new exams or edit existing ones as well as students participating in the exams. The system was built using. Various open source technologies HTML, PHP, AJAX and MYSQL database are used in this system. An autograding module was generalized to enable different exam and question types.

\section{PROPOSED SYSTEM AND IMPLEMENTATION}

The purpose of proposed system is to develop a system of improved facilities. The proposed system can overcome the limitations of the existing system. The system reduces the manual work and provides proper security. The existing system has several disadvantages and many more difficulties to work well. The proposed system tries to reduce these difficulties up to some extent. The proposed system will eliminate the inefficiencies of the current system as it will integrate the use of information technological tools to aid in the running and management of tertiary institutions in developing countries like Nigeria. The new system will also enhance the development of quality service of management which will in turn, ensure that students are not subjected to undue suffering in collection of their transcript or clearance prior to the deployment for youth service.

\section{IMPLEMENTATION}

The Enhanced Exam Management System will be implemented using a three tier distributed architecture with a database server for information storage, a middleware application and a client side application. The client side will be designed using HTML (Hypertext Markup Language) and will be viewed with a web browser. The records and information about the school will be stored using the MySQL online database server while the middleware application will be implemented using the PHP server side scripting language.

\section{USE CASE DIAGRAM}

The unified modeling language used is use case diagram. A use case is a set of scenarios that describes an interaction between a user and a system. A use case diagram displays the relationship among actors and use cases. The two main components of a use case diagram are use cases and actors. The actors in our system are Students, Lecturers, HOD and Admin. The use case diagram is designed below 


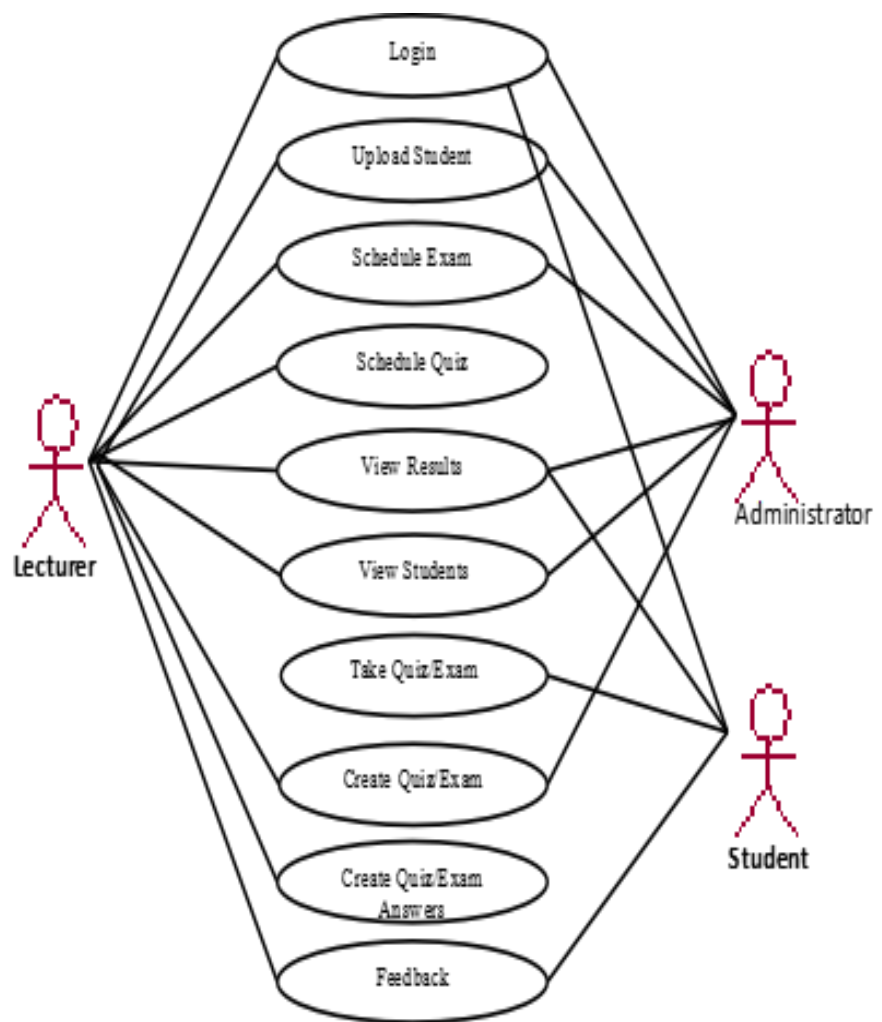

Fig. 1 Use Case Diagram of the Proposed System

\section{CLASS DIAGRAM}

The Class Diagram of the Proposed System is displayed below:

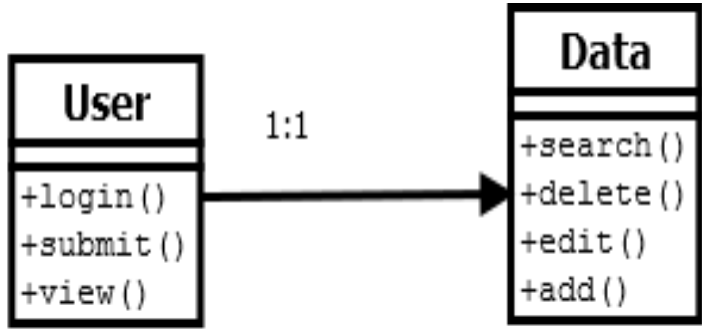

Fig 2. Class Diagram of the Proposed System

\section{INTERACTION DIAGRAM}

The Interaction of the Proposed System is displayed below:

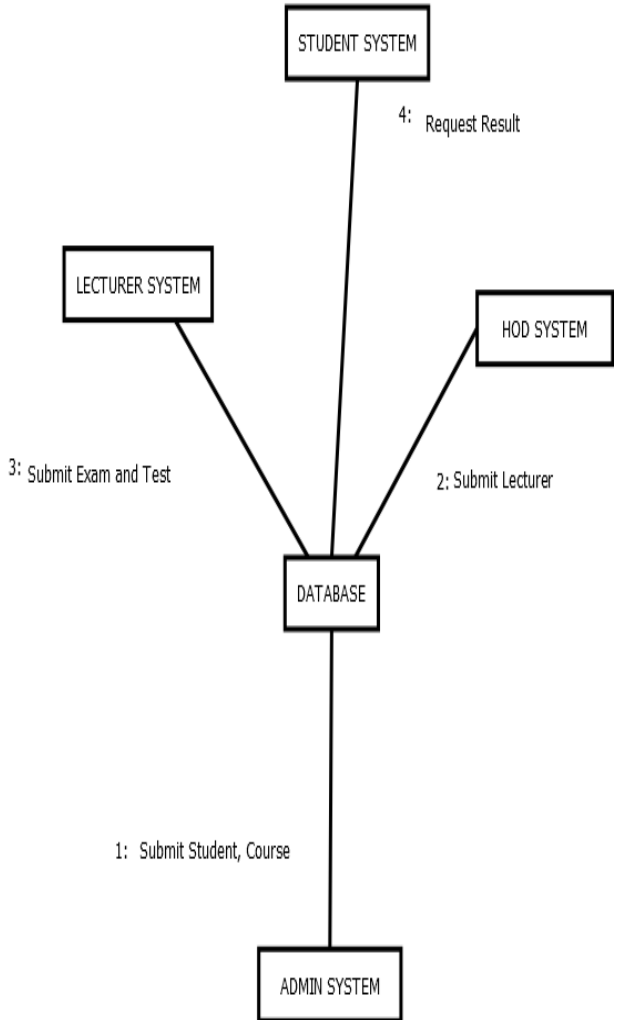

Fig 3. Interaction Diagram of the Proposed System

IX. ARCHITECTURE FOR THE PROPOSED SYSTEM

The Architecture of the proposed system is illustrated below:

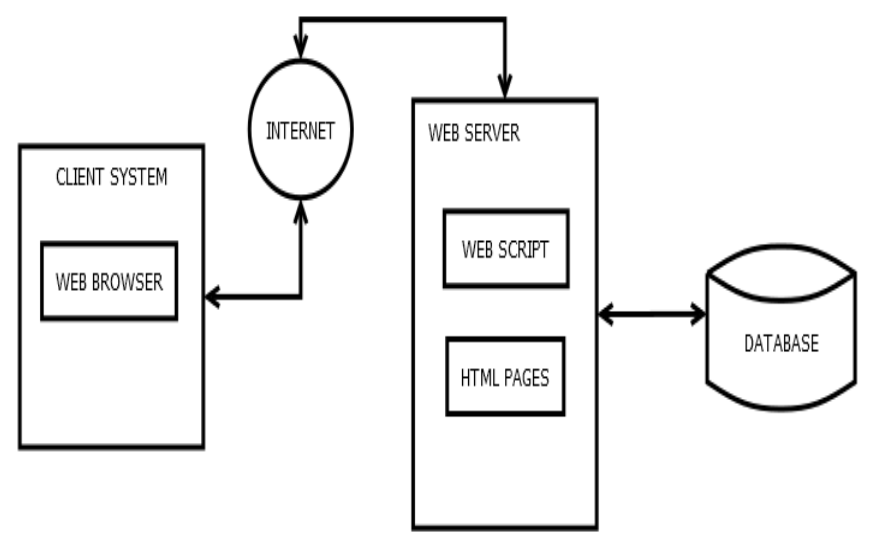

Fig 4. Architecture of the Proposed System

X. DESCRIPTION OF INPUT- OUTPUT FORMAT

\section{A. Input Format}


The input format for the proposed system is displayed below:

System Login Form: This form lets the user submit login details to gain access into the system.

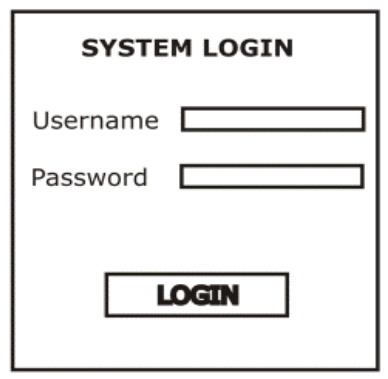

Fig 5. Login Interface

Lecturer Registration Form: This form is used by the Head of Department to register the lecturers into the system.

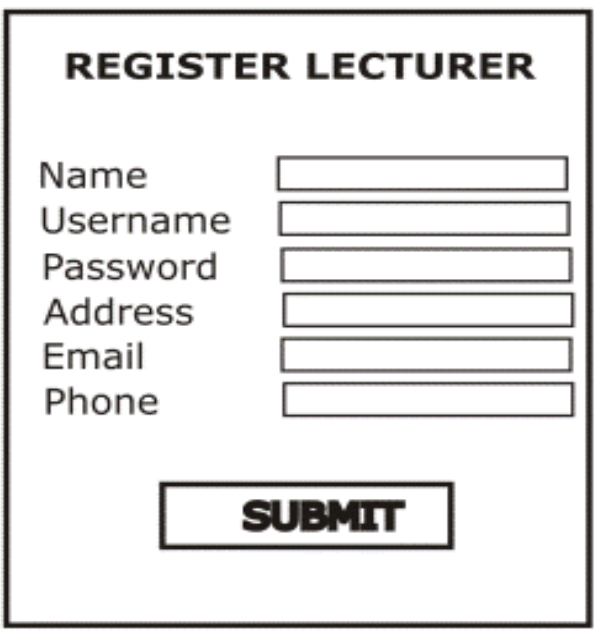

Fig 6. Lecturer Registration Form

Student Registration Form: This form is used by the Records Unit Officers to register the students into the system.

\section{REGISTER STUDENT}

\section{Name \\ RegNumber \\ Password \\ Sex \\ Department \\ Level}

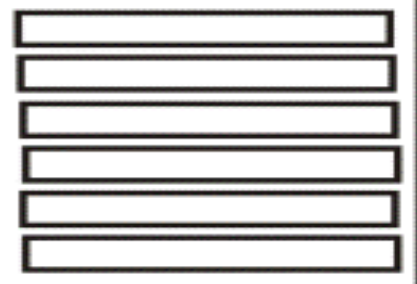

SUBMT
Course Registration Form: This form is used by the Records Unit Officers to register the courses offered in the school into the system.

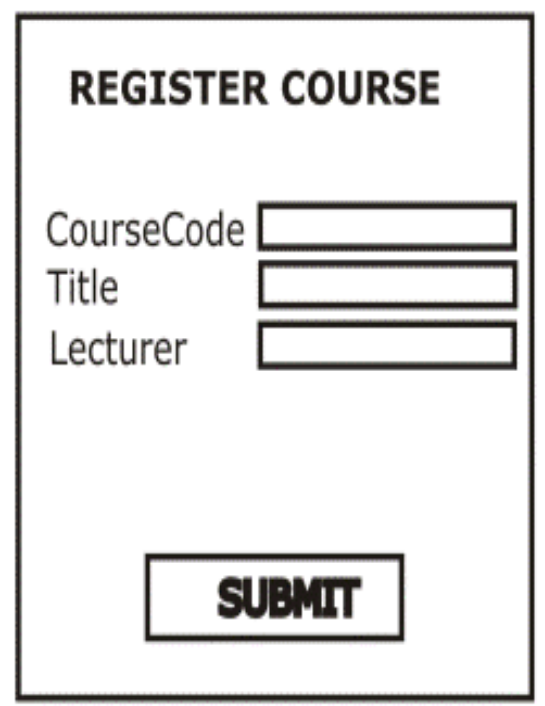

Fig 8. Course Registration Form

\section{B. Output Interface Design}

Student Result Page: This page displays information about the students' result on the continuous assessment and examinations written. 


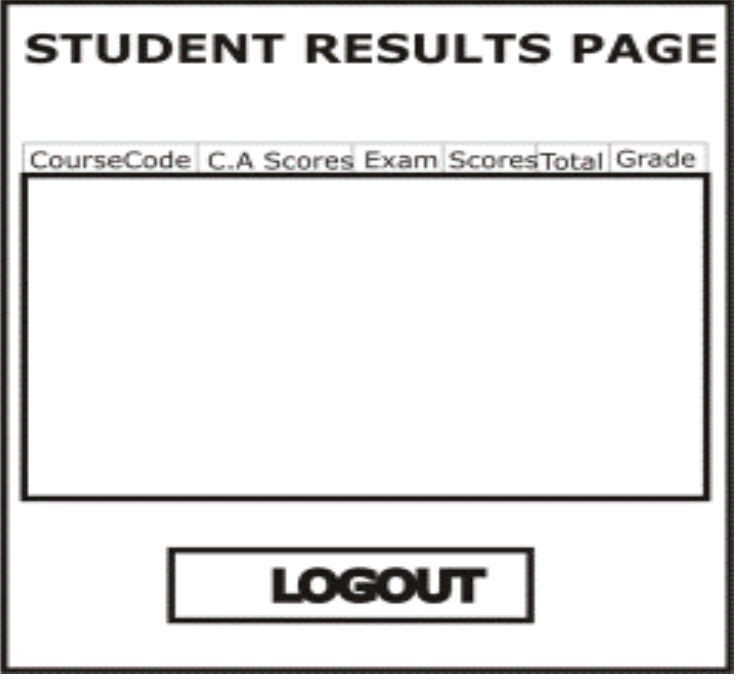

Fig 9. Student Result Window

Score Record Form: This form is used by the Lecturers to view the students' scores.

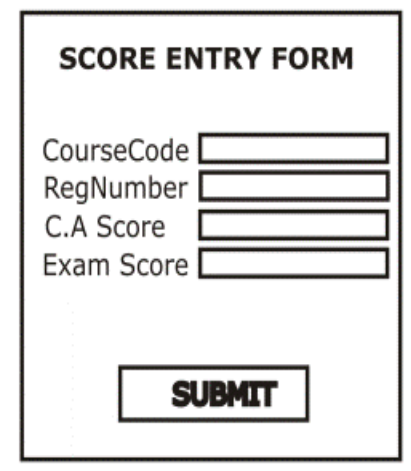

Fig 10. Score Card

\section{ALGORITHM OF THE PROPOSED SYSTEM}

The algorithm for the examination module of the proposed system is shown below:
1. Start
2. Login
3. Select CA
4. Start Test
5. Submit Answer
6. View Result
7. Select Exam
8. Start Exam
9. Submit Answer
10. View Result
11. End

\section{INFORMATION AND PRODUCT FLOW DIAGRAM}

The product flow diagram is a representation of the order of sequence by which a sequence of the product is created according to the product breakdown structure.

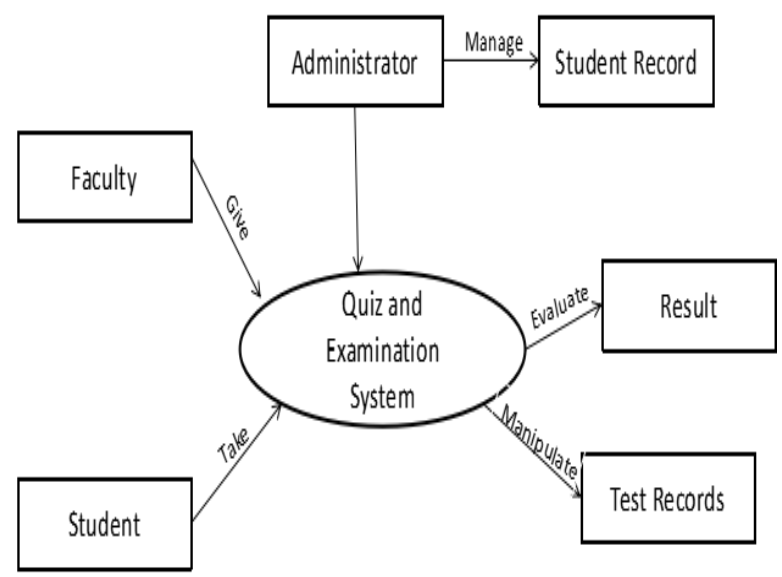

Fig 11. Information and Product Flow Diagram for the Proposed System

\section{OVERVIEW DESCRIPTION OF THE NEW SYSTEM}

These are explained using the program modules used to design and implement the quiz and examination system

Logout: Logout enables the student to return to the login page, after writing the exams. The admin can also log out after performing any task on the system.

Create Exam: Create an exam as the name implies enables admin to create exams. This module is strictly for the admin. The admin clicks the link, enters the exam name and the score is allocated to the exams, and click submit.

Create Questions: Create questions as the name implies enable admin to create questions. The user clicks on the link, select the exams that he/she wants to create questions for, type the question number, input the question, input the correct options, and finally clicks submit.

Register Student: For a student/user to be qualified for the examination, such a student/user must be registered. During registration, the student fills a form and upload his/her photograph. The student/user is also given login credentials i.e username, password, and a PIN. These login credentials are used by the student to write exams.

View Result: Here a score that comprises results of all the users/students that took the exams can be viewed in a document. It can as well be printed or saved. 


\section{International Journal of Engineering Applied Sciences and Technology, 2021 \\ Vol. 5, Issue 12, ISSN No. 2455-2143, Pages 33-38 \\ Published Online April 2021 in IJEAST (http://www.ijeast.com)}

\section{RESULT AND CONCLUSION}

The benefits of using an Enhanced Exam Management System cannot be overemphasized as the system will increase the speed of processing results, increase accuracy in result computation, eliminate cases of misplacing files of students and reduce the pilling up of papers in the offices. The system was able to be used to conduct examinations perfectly and all the objectives set out at the start of the research were achieved.

\section{REFERENCE}

1) Iyilade, J. S., \& Adekunle, W. O. (2005). A Web-based Student Testing and Assessment System. Teaching, Research and Administration, AICTTRA, 1, 16-24.

2) Rashad, M. Z., Mahmoud S, K., Ahmed E, H., \& Mahmoud A, Z. (2010). An Arabic WebBased Examination. International Journal of Electrical \& Computer Sciences, 10(1), 48-54.

3) Thomas Schramm (2008), "E-Assessments and E-Exams for Geomatics Studies", Department of Geomatics Hafen City University Hamburg Hebebrandstraße 1,22297 Hamburg, Germany http://www.hcu-hamburg.de/geomatik

4) Zhaozong Meng \& Joan Lu (2011). Implementing the Emerging Mobile Technology in Facilitating Mobile Exam System. Proceedings of 2nd International Conference on Networking and Information Technology, Singapore.

5) Brian, T. F. (2006). Database Design and Management ( ${ }^{r d}$ ed.). New York: Practice Hall Publishers pg 30-31.

6) Craig, S. M. (2002). Database Administration. Addison: Wesley Professional ISBN: 01741296.

7) Date, C. J. (2003). An Introduction to Database System (5 $5^{\text {th }}$ ed.). Addison:Wesley ISBN 0-201-51381-1.

8) Iwhiwhu, E. B. (2005). Management of Records in Nigerian Universities. Problems and prospects. The Electronic Library 23(30).

9) Popoola, S. O. (2000). Records Management Program in Nigeria: A Survey of Osun state Civil Service. Nigerian Libraries, 34(1).

10) Nwankwo, J. I. (1982). Establishment of Management Information. Insind Province, UNESCO Technical Report: Project PAK/77/038.
11) Adinola, T. K. (2005). Coping With the Challenges of Database.

Retrieved fromhttp://databaseentry.org/history. 2008-02-10.

12) Zhenming, Y., Zhang, Z., \& Zhan, L. (2003). A novel web-based examination system for computer science education. 33rd ASEE/IEEE Frontiers in Education Conference, S3F-7 - S3F-10, 2003. 